\title{
CHILE Y ESTADOS UNIDOS: TRES DÉCADAS DECISIVAS EN SUS RELACIONES COMERCIALES Y POLÍTICAS, 1900-1930*
}

\author{
Dr. Hernán Villablanca Zurita**
}

\section{INTRODUCCIÓN}

Como es sabido, la ruptura de Chile de su status de colonia de España en 1818 no significó el término de su subordinación económica de potencias extranjeras, que se encontraban en una fase de desarrollo económico mucho más avanzado. En efecto, desde los inicios de la república se aprecia el interés de Gran Bretaña por aumentar crecientemente sus vínculos comerciales con Chile y los otros países de América Latina a través de las oficinas comerciales que fueron adquiriendo una gran influencia económica y política durante el siglo XIX.

Aunque los Estados Unidos mantuvo una presencia regular en el intercambio comercial con Chile a lo largo del siglo pasado, su participación ocupó siempre un lugar secundario en comparación con Gran Bretaña y otros países europeos. Sin embargo, durante las primeras tres décadas de este siglo la situación se revierte, de modo que hacia el decenio de 1920 los Estados Unidos figura ya entre las potencias económicas mundiales y ha desplazado a Gran Bretaña como el socio principal y más influyente en sus relaciones económicas y políticas con Chile.

¿Cómo se produjo este desplazamiento de Gran Bretaña por los Estados Unidos? A nuestro juicio, el interés de los Estados Unidos por aumentar sus lazos comerciales e influencia en Sudamérica y Chile -y su capacidad de lograrlo- obedece a razones objetivas y subjetivas. Por un lado, la espectacular expansión económica que los EE. UU. experimenta desde el término de la Guerra de Secesión le permite incrementar su capacidad de acumulación de capitales a niveles que lo convierten -hacia fines de la Primera Guerra Mundial- en un país acreedor e inversor de capitales en el extranjero. Por otro lado, la expansión económica significó ampliar su excedente en cuanto a capitales y mercancías que debían ser colocados en nuevos mercados. En este sentido desarrolla toda una política destinada al logro de dicho objetivo, el cual es alcanzado ya en la década de 1920.

A través de este trabajo se intenta examinar cómo y qué mecanismos utilizó los Estados Lnidos, desde fines del siglo XIX, para introducirse en los mercados de los países sudamericanos, : de Chile en particular.

Este trabajo es parte de un proyecto de investigación financiado por el Departamento Técnico de Investigación (D. T. I. $\$ 3630-9312)$ de la Universidad de Chile.

Académico del Departaniento de Sociología de la Facultad de Ciencias Sociales de la Universidad de Chile. 


\section{DESARROLLO ECONÓMICO DE LOS EE. UU.}

Durante el siglo XIX el sistema capitalista mundial experimenta, especialmente durante la segunda mitad de esa centuria, un notorio proceso de desarrollo pasando a una nueva fase denominada, según autores de fines del siglo pasado y comienzos de éste, como imperialista.

Los datos que entregamos en el cuadro 1 permiten apreciar el gigantesco crecimiento de las fuerzas de producción. expresadas a través del incremento del poder de la maquinaria industrial (omitido el poder del transporte motorizado) en millones de caballos de fuerza (HP) de los principales países industrializados del mundo.

Cuadro 1: Crecimiento del Poder de la Maquinaria Industrial (en millones de HP)

\begin{tabular}{|l|c|c|c|c|c|c|}
\hline Año & Reino Unido & Francia & Alemania & EE. UU. & $\begin{array}{c}\text { Países extra europeos } \\
\text { (ex EE.UU.) }\end{array}$ & Mundo \\
\hline 1835 & 0.3 & 0.02 & 0.001 & 0.3 & 0.001 & 0.65 \\
\hline 1875 & 6.0 & 3.00 & 4.0 & 7.8 & 1.9 & 26.5 \\
\hline 1913 & 28.5 & 12.5 & 21.0 & 86.0 & 31.0 & 211.0 \\
\hline 1928 & 37.0 & 18.5 & 32.0 & 162.0 & 93.0 & 390.0 \\
\hline
\end{tabular}

Fuente: P. Dutt, Fascisn and Social Revolution, N. York, 1934, p. 5.

Podemos observar, a través de los datos, que especialmente entre 1875 y 1913 se produce un gran incremento del poder industrial del mundo en su totalidad. destacándose en dicho desarrollo en primer lugar los Estados Unidos seguido por Gran Bretaña y Alemania.

Se podría afirmar que los años que siguen a la Guerra de Secesión en los EE. UU. (18611865 ) constituyen el momento del 'despegue' económico norteamericano. A fines del siglo XIX la economía capitalista de este país había alcanzado un avance notable en su desarrollo.

La industrialización. que había conllevado la transformación de la economía agrícola preponderante hasta entonces, experimentaba una fuerte concentración, acompañada de manera similar por los sectores del transporte, las finanzas y el trabajo, la cual fue precedida por la consolidación financiera. provocando un cambio en el control de la producción. Los grandes magnates industriales fueron reemplazados o fusionados al capital bancario (H. Faulkner, 1951:4).

Esta transformación de la economía capitalista norteamericana va a tener consecuencias en el desarrollo posterior de la política de inversiones aplicada por esta nación. De país importador de capitales y de país deudor se va convirtiendo en un país exportador de capitales y en un país acreedor, especialmente desde fines de la Primera Guerra Mundial.

Alrededor del año 1900 la industria había asumido el rol principal en la economía estadounidense. El valor de los productos manufactureros alcanzó, en ese año, la suma de US S 13.010.000.000, sobrepasando de este modo largamente los US $\$ 4.717 .000 .000$ estimados para la agricultura. A su vez. el capital industrial había aumentado en más de tres mil millones de dólares entre 1890 y 1900 de US $\$ 6.525 .000 .000$ a US \$ 9.831.000, aumentando en esa década en casi un $45 \%$ el número de establecimientos. especialmente de la industria del metal. En las décadas previas la industria manufacturera había estado dedicada principalmente al procesamiento del agro y forestales. En el año 1900 el énfasis había cambiado a los productos mineros. Todo 
esto acompañado del desarrollo de un complejo sistema bancario que incluía 3.732 bancos nacionales y más de 4.000 bancos estatales (H. Faulkner, 1951: 8-10, 118).

La enorme expansión industrial de los Estados Unidos entre los años 1897 y 1917 fue acompañada por una pronunciada concentración de la producción en consorcios que efectuaban operaciones en gran escala. En el año 1919 las corporaciones representaban el 31,5\% de los establecimientos de la industria manufacturera, pero empleaban el $86 \%$ de la fuerza de trabajoobrero y producían el $87.7 \%$ de los productos.

Entre los factores que hicieron posible este gigantesco desarrollo pueden citarse los siguientes:

1. - El progreso técnico, en especial, el perfeccionamiento del poder (power generating) de las maquinarias causado por el cambio del uso de la fuerza del agua por el vapor, por el reemplazo de los antiguos motores a vapor por compactas turbinas de alta velocidad, y debido a que la introducción de la fuerza eléctrica liberó al proceso de manufacturación de la incertidumbre y las restricciones de la antigua fuerza del agua, permitiendo una expansión ilimitada. Además numerosos inventos liberaron operaciones importantes de la producción manual, haciendo posible una manufacturación rápida y en gran escala. A su vez, nuevos instrumentos y maquinarias hicieron más rápido el proceso de producción, y aceleraron el tamaño del output.

2. - Expansión del área del mercado. Dado que la producción en gran escala sólo puede existir con un mercado similar y que, a su vez, esto significa una distribución en un área más amplio, es necesario que haya medios de transportes y comunicaciones rápidos y baratos, tanto para recibir la materia prima como para distribuir el producto terminado. En este contexto la instalación de vías férreas aumentó de $30.625 \mathrm{Km}$. en el año 1860 a $198.964 \mathrm{Km}$. en el año 1906 , encontrándose toda la red ferroviaria en manos de grandes corporaciones: Vanderbilt, Pennsylvania, Morgan, Gould, Rock Island, Hill Roads y Harriman.

3. - Un tercer elemento que incidió en el desarrollo de la industria en gran escala fue el -urgimiento de la corporación. La necesidad de grandes capitales para construcciones, maquinarias nra mercancías en gran escala, se encontraba más allá de la capacidad de asociaciones o personas wsladas. Esto fue logrado mediante la corporación, o sea, a través del surgimiento del capital Inanciero. Los haberes de las instituciones financieras, incluyendo bancos nacionales, bancos de horro, bancos privados compañías de seguros de vida, se elevaron de US $\$ 9.156 .000$ millones ¿11 1897 a US $\$ 27.795 .000$ millones en 1911. Después de 1897 una gran parte del capital excedente -ntinuó dirigiéndose hacia los ferrocarriles, pero el mercado de las inversiones era ahora más mplio e incluía utilidades públicas, empresas industriales, propiedades extranjeras, y los valores - 2 gobiemo local y del Estado y aquellos del gobierno federal. Hacia la década de 1890 habían - ficientes fondos de inversión para promover negocios de grandes casas de inversión nor- americanas, y fondos norteamericanos y europeos fueron destinados a proyectos industriales y il transporte. El cambio del centro de poder económico desde el capitalista industrial al financiero - produce cuando la expansión de la industria alcanza una magnitud que encuentra más allá de s recursos de empresarios individuales, y cuando el desenvolvimiento por la consolidación zanza una fase en la cual los servicios de una casa central de inversiones se hizo necesaria para ..nejar las finanzas envueltas. Un otro paso importante más debía ser dado en el desarrollo del -.pital financiero y de su dominio de la vida económica de la nación -la integración de las grandes mpañías de seguros con las inversiones bancarias. A través de los pagos de millones, de pequeñas lizas de seguros, las compañías de seguros de vida contribuyeron con una inagotable reserva 
de capital. A medida que los capitalistas financieros llegaron a ser más poderosos tomando gradualmente el control de los bancos, el centro del interés bancario, se desplazó crecientemente de la inversión comercial a la bancaria (H. Faulkner, 1951:153-54, 187-97, 36-37).

No obstante, que los Estados Unidos muestra desde el último tercio del siglo pasado un continuo desarrollo capitalista (aunque esto no significa que haya estado exento de las cíclicas crisis económicas de la economía capitalista), hasta comienzos de la Primera Guerra Mundial todavía puede ser considerado como un país deudor y receptor de inversiones extranjeras.

Es precisamente durante los años de esa Guerra y en los siguientes cuando los EE. UU., pasan a transformarse en un país acreedor. En el año 1914 los Estados Unidos se encontraban en medio de una depresión industrial la que desde el punto de vista del comercio internacional, se expresó mediante una reducción de las mercancías de exportación sobre las de importación (L. C. Sorrell, 1916:25).

Esta situación comenzó a cambiar inmediatamente después del inicio de la Primera Guerra Mundial, ya que en los dos años previos a su declaración de Guerra a Alemania (en Abril de 1917), la economía norteamericana había sido estimulada por la venta de mercancías a los países europeos en guerra (L. Sorrell. 1916:29). A su vez. los empréstitos contraídos en los EE. UU. por los Aliados más la cantidad obtenida por la venta de sus valores significó por lo mismo 5.000 millones de dólares de poder comprador en la economía norteamericana entre Enero de 1915 y Abril de 1917 lo cual constituyó un porcentaje substancial dei ingreso nacional total de esa época, que provocaba un enorme auge económico que no se limitaba sólo a la producción de armamentos y municiones de guerra. sino también a productos del agro y de la minería: desde el inicio de la guerra hasta junio de 1917 los países aliados compraron en los Estados Unidos casi siete veces más del valor en trigo en comparación con los tres años previos a la guerra. compraron dos veces más harina de trigo, aproximadamente dos y medio veces más de carne, casi cuatro veces más de azúcar, y treinta y siete veces más de zinc (G. Soule. 1947:7).

Puede apreciarse además que desde fines de la guerra hasta la crisis económica de 1929 con breves lapsos de recesión económica entre 1918 y 1919 y durante el año 1921 - la economía norteamericana mostró un regular proceso de prosperidad y expansión. Desde el punto de vista técnico, la industria estadounidense no tuvo mayores dificultades para que sus establecimientos y maquinarias volvieran a poner sus capacidades para la producción civil. Así, por ejemplo, la producción de automóviles aumentó de 1.750 .000 unidades en el año 1917 a 1.900 .000 en 1920. Sin embargo. parece ser que el factor más influyente en la expansión económica norteamericana fue el alto nivel de las exportaciones debido. en gran parte. al hecho de que los préstamos que los EE. UU. continuaban haciendo a los países europeos aliados eran gastados principalmente en la compra de productos de procedencia norteamericana. beneficiándose especialmente los productos de exportación de la agricultura y. en menor grado. los de la industria manufacturera. Por su parte. el ingreso nacional se elevó de 56,5 mil millones de dólares en el año 1921 a 87.000 millones en 1929 (G. Soule. 1947: 85.87. 107).

Asimismo. el decisivo impulso experimentado por los círculos financieros durante la Primera Guerra Mundial y en la década siguiente. le permitió a los EE. UU. asumir un nuevo papel en el plano económico internacional al transformarse de país deudor en país acreedor! exportador de capitales. La inversión agregada extranjera en los Estados Unidos se redujo de 7.2 mil millones de dólares en 1914 a aproximadamente 4 mil millones de dólares en 1919, y en este mismo año las deudas extranjeras contraídas con los Estados Unidos sobrepasaban las deudas de 
este país con el extranjero en 12.562 millones de dólares. Lo mismo se aprecia en el campo de las finanzas internacionales: antes de la guerra los diversos países europeos que participaron en ella prácticamente no tenían deudas con los EE. UU., después de la guerra éstas alcanzaban la suma de 9.591 millones de dólares (G. Soule, 1943: 254-55).

El incremento del excedente económico a los Estados Unidos también se reflejó en un aumento de sus préstamos e inversiones directa en Sud América, ampliando y reforzando su política de expansión económica, y asumiendo con mayor fuerza su nuevo papel hegemónico en el sistema capitalista mundial.

\section{LA EXPANSIÓN ECONÓMICA NORTEAMERICANA EN CHILE}

Aunque los términos 'esferas de interés' o 'esferas de influencia' no tenían entonces la difusión que tienen hoy en día, puede decirse que políticos norteamericanos tenían en mente convertir a las repúblicas latinoamericanas que recién se emancipaban de su status colonial en un territorio que se ajustase a las pretensiones económico-territoriales de los Estados Unidos. Aún cuando existen antecedentes de que dichos objetivos expansionistas ya pueden ser percibidos a fines del siglo XVIII (S. Nearing y J. Freeman, 1969:233), la primera expresión internacional de tales proyectos se efectuó en el año 1823 por el presidente norteamericano J. Monroe en su declaración conocida como 'Doctrina Monroe'.

Pese a que algunos autores han sostenido posteriormente que el presidente Monroe estaba guiado por un espíritu altruista y desinteresado que sólo perseguía oponer una barrera infranqueable a las pretensiones de la Santa Alianza de reivindicar para España los dominios independizados, y que la Doctrina Monroe fue alterada en su interpretación por los presidentes de los Estados Unidos posteriores a J. Monroe, no cabe duda que la mencionada Doctrina abrió las puertas a la expansión de ese país en la región latinoamericana (E. Molina, 1918:512; F. B. Loomis, 1903:2).

Ha sido posible constatar que entre los años 1800 y 1969 se registraron 771 intervenciones (entendidas como formas de intervención: las protestas diplomáticas, las acusaciones, las amenazas, las sanciones, el retiro de embajadores, la ruptura de relaciones diplomáticas, las movilizaciones, los castigos, las vejaciones y actos de provocación, los bloqueos, las intervenciones encubiertas; las intervenciones militares abiertas, las intervenciones colectivas, las conspiraciones, los actos de espionaje y los tratados que afectan la soberanía) extranjeras en América Latina, siendo los países más afectados, por todo tipo de intervenciones y por grandes potencias en general, México (270), Cuba (92), Guatemala (61), y la República Dominicana (60) (P. González Casanova, 1978: $20-23)$.

Sin la intención de simplificar esquemáticamente, se podría decir que la política expansionista de los EE. UU. hacia América Latina presenta dos momentos bastante claros durante los siglos XIX y XX. En el primer período, que se extiende desde alrededor del año 1820 hasta los años 1875/85, la expansión norteamericana tiene esencialmente un carácter territorial y comercial. El mismo presidente Monroe. que con su declaración ponía barreras a la ingerencia de las potencias europeas en América Latina, inició una ofensiva política destinada a ampliar los vínculos comerciales con los países de esta región. Con este fin, entre 1822 y 1825 , se enviaron agentes consulares o consules a las principales ciudades de los nuevos Estados Latinoamericanos los que prontamente comenzaron a enviar a Washington valiosos informes sobre las condiciones politicas y economicas de sus respectivos distritos. Después de a gunos anos las agencias consulates 
norteamericanas se hallaban ampliamente distribuidas a través de los países de la región, y a la vez éstos enviaban cónsules a los puertos y ciudades importantes de los EE. UU. (W. S. Robertson, 1923:193-4). Simultáneamente se iniciaron conversaciones con el propósito de establecer tratados comerciales con los distintos países latinoamericanos. El principio general de la política comercial norteamericana en estos primeros tratados se fundamentaba en el deseo de regular su comercio con estas naciones. Dentro de estas regulaciones se contemplaba, sin embargo, tal como fue expresado en las conversaciones con el gobierno de Colombia, que los Estados Unidos -aunque no exigían ningún privilegio para sí- confiaban en que Colombia no otorgaría ningún privilegio a otras naciones. Así, en el tratado de amistad, comercio y navegación suscrito por esos dos países en el año 1825 se estipuló que ninguna de las naciones contratantes garantizaría algún beneficio especial en lo relativo a comercio y navegación a una tercera nación que no fuese de inmediato común a la otra parte. En las conversaciones con México, y dado que este país tenía la intención de negociar tratados con repúblicas hispanoamericanas concediéndoles especiales privilegios comerciales que no eran garantizados a ningún otro país, el representante norteamericano objetó tales propósitos sosteniendo que no debería hacerse ninguna distinción entre las naciones americanas. Se argumenta además que el tratado con Colombia no contiene tal disposición, entonces, se utilizan como precedentes establecidos los acuerdos alcanzados en otros tratados bilaterales previos. Prevalecieron los argumentos norteamericanos y con esas características fue firmado el tratado con México en 1831. Con la inclusión de estos criterios los Estados Unidos suscribe sus tratados con Ecuador y otras naciones latinoamericanas. En los años 1850 y 1860 los Estados Unidos y las potencias europeas logran nuevos beneficios en el campo de las relaciones comerciales con América Latina al obtener la libre navegación internacional en los ríos de la región (W. S. Robertson, 1923:193, 209).

Chile y los Estados Unidos suscribieron su primer tratado de amistad, comercio y navegación en el mes de mayo de 1832 . Regiría por un período de doce años y se fundamentaba en las prácticas establecidas en otros pactos suscritos por los EE. UU. Se reconocía la libertad de comercio entre las dos naciones, se declaraba que ninguna de ellas podría conceder a terceros privilegios especiales que no fueran extensivos a las partes contratantes. Pero, en este punto Chile exceptuaba las concesiones hechas o que pudiera hacer, por razón de identidad de origen y de unidad de intereses políticos, a los otros Estados hispanoamericanos. Por otra parte, los ciudadanos de cada uno de los países contratantes gozarían en el otro de todos los derechos de los naturales para residir, traficar, comerciar y disponer de sus bienes, con la facultad de heredar por testamento o ab-intestado. En la eventualidad de una guerra entre los dos Estados contratantes, la propiedad y persona de los ciudadanos de uno de ellos que residiese en el otro, quedaban garantizadas, por reglas tan liberales como equitativas, de modo tal que aquella no podría ser secuestrada en ningún caso, ni éstos privados de su libertad y las garantías reconocidas en tiempo de paz, dándose a los comerciantes del país enemigo el término de seis meses o de un año, según el lugar que residieran, para arreglar sus negocios y transportar sus efectos. Los últimos artículos de este pacto fijaban el tratamiento y garantía de los ministros diplomáticos y de los cónsules, colocándolos bajo el pie que cada una de las partes contratantes acordase a los agentes de la nación más favorecida, y comprometiéndose ambas partes a celebrar más tarde una convención consular (D. Barros Arana, 1892: vol 16, p. p. 174-76).

Junto a estos tratados de amistad, comercio y navegación los Estados Unidos aplicaron también una política de uso de la fuerza para su expansión económica. En el año 1845, el presidente Polk, ante la posible intervención de potencias europea por la anexión de Texas, dio un nuevo significado a la Doctrina Monroe, al restringir la aplicación de la expansión 'no más colonias europea en este continente' sólo a Norte América. (F. Loomis, 1903:5). 
Pese a las críticas que despertaban las continuas intervenciones de los EE. UU. en A. Latina entre los políticos de esta región y juristas europeos, ese país prosiguió aplicando su política expansionista, acentuándose a partir de la década 1870-80 cuando el fortalecimiento de su economía conlleva la concentración de la producción en monopolios (en sus diversas formas) y se une el capital bancario con el industrial.

\section{PERÍODO 1880-1938}

Hacia el año 1875 la relación del intercambio de los EE. UU. con América Latina era desfavorable a ese país. Se estima que las exportaciones norteamericanas a Latinoamérica alcanzaban la suma de 28.627.909 dólares en tanto que sus importaciones desde esta región era de 78. 291. 858 dólares (W. S. Robertson, 1923; 204, 210).

A partir de los años 1880 la política norteamericana destinada a penetrar en los mercados de América Latina y de Sudamérica en particular puede dividirse en dos subperíodos o etapas: una primera que se extiende hasta comienzos de la Primera Guerra Mundial durante la cual procura elevar su participación comercial en los mercados de la región, compitiendo con Gran Bretaña y Alemania principalmente y una segunda fase que se prolonga desde fines de esa guerra y las dos décadas siguientes en la cual consolida su posición económica y procura reestructurar las economías e instituciones económicas de estos países con el propósito de adecuarlas e incorporarlas a la política económica global de los Estados Unidos.

De acuerdo a la distribución por país de las exportaciones estadounidenses en el año 1891, los países sudamericanos eran clasificados en tres grupos: a) la región de la Plata, constituida por Argentina, Uruguay y Paraguay. b) la región tropical, conformada por Brasil, las Guayanas, Venezuela y Colombia; y c) la región montañosa que comprendía a Chile, Perú, Ecuador y Bolivia. Según esta clasificación los países incluidos en la región de La Plata se dedican a la agricultura y a la ganadería, siendo de gran importancia para los EE. UU., como fuente de productos de cueros y lanas de los cuales Norteamérica absorbe un tercio de la exportación de cueros y un séptimo de la producción de lanas. Pero, las importaciones que efectuaba esa región provenían casi en su totalidad de Europa, especialmente de Gran Bretaña que satisface los dos quintos de la importación total de Argentina, en tanto que los Estados Unidos se halla en el quinto lugar en cuanto al volumen total de las importaciones de ese país.

Con relación al grupo de los países tropicales la situación era diferente por la existencia de un intercambio más estrecho con los Estados Unidos, siendo Brasil el mayor comprador de los productos norteamericanos.

Los países denominados montañosos de la Costa del Pacífico se encuentran en una situación intermedia, porque su intercambio comercial con los EE. UU. es mayor que los de la región de La Plata pero menor que el de los países tropicales. Hacia los años 1880-1900 el comercio con Chile aumentaba rápidamente. Los Estados Unidos prácticamente tenían el monopolio en cuanto al comercio de implementos agrícolas. maderas. petróleo. con respecto al volumen de los negocios del abastecimiento de comestibles, autos carruajes y manufacturas de maderas. También los Estados Unidos abastecían el mercado chileno con medicinas, algodón crudo y textiles, productos de cuero y caucho, papel. vidrio. tabaco. y ciertas manufacturas de fierro y acero. Sin embargo. la mayor parte de las importaciones chilenas aún procedian de Gran Bretaña, especialmente las manufacturas de algodón. hierro y acero (F. R. Clow, 1893:194-98). 
Según analistas norteamericanos de la época, la falta de un mayor desarrollo del intercambio comercial con A. Latina y, en particular, con los países sudamericanos se debía, entre otros, a las razones siguientes:

1) Insuficiente conocimiento de las condiciones de los distintos mercados de la región, de sus costumbres, idioma, hábitos de consumo, etc.

2) La difundida creencia entre los hombres de negocios norteamericanos de que Europa era un campo más apropiado para los esfuerzos destinados a la exportación de productos norteamericanos (lo cual era válido mientras los EE. UU. fue básicamente un productor de materias primas minerales y agrícolas y de alimentos en general que encontraban su mercado lógico en los conglomerados manufactureros de Europa, pero esto cambia cuando se transforman en un país productor de artículos manufacturados).

3) A diferencia de los países europeos, los EE. UU. no disponían de un desarrollo sistema comercial que les permitiera ampliar y perpetuar su comercio (facilidades de transportes y comunicaciones, agencias comerciales, sistema de créditos, etc.).

4) Insuficientes inversiones públicas y privadas debido a la falta de un sistema bancario financiero que, junto con facilitar y agilizar los trámites comerciales, proporcionase un apoyo a las inversiones y créditos estadounidenses que a su vez, impulsasen la compra de productos norteamericanos ('el comercio sigue a los préstamos e inversiones').

5) Carencia de una adecuada propaganda comercial de los productos norteamericanos los cuales, de acuerdo a informaciones consulares, tienen una recepción y aceptación similar a los de origen europeo. (D. Kinley, 1911; F. Clow, 1893; F. Emory, 1904; W. C. Downs, 1912; H. M. Kahler, 1911; W. H. Schoff, 1911).

Todo esto indica que para que los EE. UU. amplíe su comercio en la región sudamericana era necesario que adoptara medidas destinadas a ganar la confianza de los gobiernos y de los hombres de negocios de estos países.

Para tal efecto los Estados Unidos aplicarán simultáneamente dos políticas que persiguen el mismo fin. Por un lado, prosiguen su política hegemonista de intervenciones e ingerencias en los asuntos internos de los Estados Unidos haciendo uso de la fuerza, etc., la cual fue justificada mediante la doctrina conocida cono del 'Destino manifiesto' que sustentaba la tesis evolucionista de la supervivencia de los más fuertes, sosteniendo que la superioridad anglo-sajona (del 'hombre blanco') tenía la responsabilidad de velar por el bienestar de los pueblos. La política derivada de esas concepciones, más conocida como la del 'gran garrote', fue compartida y seguida por influyentes políticos norteamericanos que, junto con los secretarios de estado James Blaine y John W. Foster, trabajaron armoniosamente en la promoción de los intereses y soberanía norteamericana en El Caribe y el Pacífico, esto es, en la aplicación de una política que significaba la expansión de los intereses económicos norteamericanos en áreas extranjeras (H. Faulkner, 1917:11-12).

Por otro lado, hacia fines del siglo pasado hombres de estado norteamericanos comenzaron a delinear la política conocida como Panamericanismo Progresista, la cual perseguía básicamente la expansión comercial, el desarrollo de nuevas oportunidades de inversiones y la búsqueda de fuentes de materias primas agrícolas y materiales en América Latina. Para tal efecto recurría a los 
líderes de las repúblicas latinoamericanas que estimaban el progreso económico como algo esencial para sus estados, que reconocían la necesidad de la participación de los capitales foráneos, y que parecían aceptar el status secundario que la política del Panamericanismo Progresista colocaba a sus países. Pero, si bien esa política estaba dirigida hacia toda América Latina, quizás el impacto más profundo de ella estuvo en América del Sur (R. N. Seidel, 1973: 2-3).

\section{LAS CONFERENCIAS PANAMERICANAS}

La Primera Conferencia Panamericana Internacional de Estados Americanos, convocada por los Estados Unidos, se celebró en Washington entre octubre de 1889 y abril de 1890 . Entre sus resoluciones una de las principales fue la creación del Buró Comercial de las Repúblicas Americanas, y en el informe del Comité sobre Regulaciones Aduaneras se sugirió que los estados se unan para el establecimiento de un Buró encargado de recoger, tabular y publicar en inglés, español y portugués, información sobre la producción y el comercio, así como sobre las leyes de aduanas y las regulaciones en sus respectivos países (C. B. Cassey, 1932: 438-9).

En Abril de 1890 la Unión Internacional de Repúblicas Americanas (nombre adoptado entonces para la organización americana que se constituía) creó el Buró Comercial de las Repúblicas Americanas. Aunque teóricamente este organismo debía trabajar en beneficio de todas las repúblicas americanas, en la práctica se hizo evidente que el buró era desvirtuado por el hecho de encontrarse bajo el control directo del Secretario de Estado de los EE. UU. (como presidente) y otros cuatro miembros elegidos en rotación entre los representantes diplomáticos de los países latinoamericanos en Washington (C. B. Cassey, 1932:441).

Al mismo tiempo en esta Primera Conferencia, y debido especialmente a la influencia ejercida por el miembro de la delegación norteamericana y miembro del comité sobre Ferrocarriles Henry Davis (acaudalado constructor de ferrocarriles), se adoptó una resolución mediante la cual se instaba la construcción de un ferrocarril intercontinental que conectara las capitales y las principales ciudades de todas o la mayoría de las naciones representadas en la Conferencia, sugiriéndose, entre otros, que dichas naciones apoyasen el proyecto con generosos concesiones de terrenos y subsidios (J. A. Caruso, 1951: 610).

El período comprendido entre la Primera y la Cuarta Conferencia efectuada en el año 1910 -Conferencia en la cual el Buró Internacional de Repúblicas Americanas adopta el nombre de Unión Panamericana- puede ser considerado como de consolidación y reorganizaciones contínuas de todos los cuerpos que conformaban esta organización, a la vez que los Estados Unidos lograba ya éxitos significativos en algunas de aquellas áreas que obstaculizaban su comercio con Sudamérica, entre los cuales se pueden mencionar los siguientes:

1. Logro de un mayor clima de confianza y de acercamiento con los gobiernos de A. Latina y en especial, sudamericanos. Al respecto la visita del Secretario de Estado norteamericano a la Tercera Conferencia efectuada en Rio de Janeiro en el año 1906 fue considerada por los delegados estadounidenses, en su informe sobre la conferencia, como una contribución a las relaciones con América Central y del Sur como nunca antes en la historia diplomática de los Estados Unidos (The Third International Conference at Rio de Janeiro, 1934:438). En Términos similares se expresó la prensa norteamericana y el delegado a la Segunda Conferencia Ch. Pepper.

El 'Times-Democrat' de New Orleans señalaba que uno de los resultados de la visita de 
Mr. Root sería el fortalecimiento de las relaciones comerciales entre los Estados Unidos y Sudamérica, y Pepper, a su vez, sostenía que la visita del Secretario de Estado servirá para remover muchas de las causas de desconfianza y aclarar muchas mal interpretaciones de los propósitos y de las políticas de los Estados Unidos (id: 439).

En América del Sur, Felipe Barreda, Profesor de Historia Panamericana de la Universidad de San Marcos de Lima, era igualmente optimista al sostener que el Panamericanismo significa libertad para siempre de todo peligro de imperialismo político y económico o de esclavitud. Según sus palabras, el Panamericanismo es fraternidad y asociación sin privilegio o discriminación. sin jactancia de superioridad, por un lado, y de humillación, temor o ansiedad, por el otro ( $F$. Barreda, 1927: 811). Sin embargo. otros sectores de la opinión pública sudamericana no compartían el mismo entusiasmo. El diario' El Chileno' de Santiago expresaba cierta inquietud con relación a la mencionada visita de Mr. Root, manifestando que el momento en que la influencia de los Estados Unidos pierda el carácter sereno y pacífico que está representado en el Sr. Root, puede ser cambiado rápidamente, por un acceso de exagerado imperialismo, en una amenaza real (The Third Conference..., 1932: 442).

Pero, mientras el Secretario de Estado de los Estados Unidos visitaba América del Sur para promover la política del Panamericanismo Progresista, el presidente de ese país, T. Roosevelt (1901 - 1909) proseguía la política de convertir a EE. UU. en la nación hegemónica del continente occidental supeditándola a su esfera de influencia. y sostenía que era deber de los Estados Unidos el uso de la fuerza militar estadounidense para asegurar el arreglo de todas las disputas en América Latina y para proteger la vida y la prosperidad tanto de europeos como de norteamericanos si ellas fuesen amenazadas ya que de no hacerlo así las potencias europeas podrían venir y establecerse permanentemente en el continente occidental y de este modo amenazarían la seguridad nacional de los EE. UU. (H. Shipstead, 1927:883).

2. Incremento de las inversiones estadounidenses en América del Sur. Las inversiones directas de los Estados Unidos en Sudamérica aumentaron de 37.9 millones de dólares en 1897 a 104.3 millones de dólares en 1908 y a 323.1 millones de dólares en 1914. Esto es, mientras que entre los años 1897 y 1908 el porcentaje de las inversiones directas totales de los Estados Unidos en América del Sur, con relación a sus inversiones totales en el mundo, permanecieron prácticamente idénticas ( 5.9 y $6.3 \%$ respectivamente), en el año 1914 sus inversiones directas en esta región de América Latina equivalía al $12 \%$ de sus inversiones directas totales. Ahora, si agregamos a las inversiones directas las de portafolio de los EE. UU. en América del Sur se puede apreciar que en el año 1897 ellas constituían el $5.5 \%$ del total de sus inversiones extranjeras, en 1908 el $5.1 \%$, y en el año 1914 el 10.4\% de sus inversiones mundiales totales (C. Lewis, 1938:606).

Con relación a las inversiones directas norteamericanas en Chile los datos varían según los diferentes autores. De acuerdo a Charles F. Speare, las inversiones estadounidenses en Chile, en el año 1909, equivalían a 12 millones de dólares (en la explotación del salitre), y según John B. Osborne, en el año 1911 el monto de esas inversiones se habría elevado a 15 millones, sin especificar el sector de la inversión (C. Lewis, 1938:608-10). Hernán Ramírez N. considera que las inversiones de capital norteamericanos fueron exiguas con anterioridad al año 1900 , estimándose que hacia ese año las inversiones de los Estados Unidos en Chile pueden ser evaluadas en unos cinco millones de dólares. Según ese autor, el ritmo de penetración del capital norteamericano se aceleró notablemente entre los años 1901 y 1914, orientándose principalmente a las actividades mineras, estimando que el valor de las inversiones se aproximaban a los 200 millones de dólares en el año 1914 (H. Ramírez N.. 1966:227-28). Por su parte. según Fred Rippy en el año 1897 el monto de 
las inversiones de capital de los EE. UU., en Chile equivalían a 2 millones de dólares, elevándose esta cifra en 1914 a 170 millones de dólares, de los cuales 169.8 millones correspondían a inversiones en la minería y 600 mil dólares en bonos del gobierno (F. Rippy, 1949:19 y 22).

3. En cuanto al intercambio comercial puede observarse un incremento de las exportaciones norteamericanas hacia América del Sur, aumentando de un valor de 23.190.220 dólares en el año 1880 a 132.310 .451 dólares en 1912. Sin embargo, el valor de sus importaciones era de 215.089 .316 dólares, de modo que el valor desfavorable de su intercambio comercial equivalía a 82.778 .865 dólares (B. Kaufman, 1971:34344).

4. Finalmente, un cuarto resultado conseguido por los EE. UU. hasta la Cuarta Conferencia Panamericano, en 1910, se refiere a la construcción del ferrocarril panamericano. De acuerdo al informe del Comité Permanente, entregado en el mes de junio de ese año, se habían construido hasta entonces 6.013 millas del ferrocarril, faltando trozos de 4,199 millas, indicándose además que la presencia del ferrocarril había desarrollado los recursos de las diferentes repúblicas de manera tal que su comercio había aumentado de 880 mil de dólares en 1890 a 2 millones de dólares en 1909 (J. A. Caruso, 1951:629-30).

Posteriormente, durante los años de la Primera Guerra Mundial, este proyecto fue prácticamente olvidado, pese a que el Comité Permanente de los Ferrocarriles continuó sus funciones. Más tarde, en mayo de 1919, el proyecto elaborado por la Comisión del Ferrocarril Internacional fue cuestionado por uno de los delegados de la República Argentina, en el Centro Nacional de Ingenieros en Buenos Aires, sosteniendo que el terreno de la ruta proyectada presentaba demasiadas dificultades ingenieriles para la construcción práctica del ferrocarril, que podía ser ruinoso para el estado financiero de las naciones de América del Sur, y que no correspondía a las condiciones de la masa geológica de la tierra del continente. Sugería, a su vez, que una mejor ruta podría ser encontrada a través de la llanura de la región Este de los Andes, proponiendo una nueva ruta geográfica desde la Sierra de Darién (en la zona fronteriza de Panamá y Colombia) hasta la parte norte de Argentina (J. A. Caruso, 1951:632-33). Todo parece indicar que las observaciones y el nuevo proyecto presentado por el ingeniero argentino correspondian más adecuadamente a las características topográficas de los territorios y de los intereses de las naciones latinoamericanas. Esto se reflejó en la conferencia de ingenieros latinoamericanos efectuada en Agosto de 1922 en Buenos Aires en la cual los delegados, en medio de grandes aplausos, adoptaron una resolución en la que establecían que la nueva ruta propuesta tomaba mejor en cuenta las características de la mayor parte del terreno de la región. Al mismo tiempo, un delegado chileno urgía, a través de una exposición escrita, a que las naciones de América del Sur estimularan la construcción de ferrocarriles en sus fronteras y a estandarizar las medidas de sus vías férreas para facilitar las relaciones comerciales entre ellos. Con esto se dio inicio a una serie de discusiones sobre nuevas variantes -a causa de que el Comité Permanente de los Ferrocarriles ignoró la proposición del delegado argentino, que se prolongaron hasta 1928 cuando algunas de las repúblicas comenzaron a rechazar tal proyecto en general, inclinándose a favor de la construcción de la Carretera Panamericana. Aunque en diciembre de 1933 fueron aceptables las sugerencias del delegado argentino, y del chileno, puede sostenerse que tal acto no fue más que algo formal ya que en los años siguientes declinaba visiblemente la construcción de ferrocarriles en toda América Latina. El desarrollo de redes de carreteras y del transporte aéreo, y las dificultades y los altos costos de la construcción del ferrocarril en las regiones andinas, inclinó a estos países a favor de los argumentos de los Estados Unidos y de las naciones centroamericanas de que el ferrocarril era algo del pasado y de que el futuro medio de transporte lo sería la carretera Panamericana (J. A. Caruso, 1951:633-37). 
No obstante que entre la Cuarta (1910) y la Quinta Conferencia Panamericana medió un período de trece años, puede sostenerse que esos años fueron decisivos en la consolidación económica norteamericana tanto en Europa como en América Latina. Al desencadenarse la guerra en Europa (1914) el gobierno estadounidense efectuó avances significativos en su política económica con relación a América Latina. Y, aunque el ingreso de los Estados Unidos en el conflicto bélico complicó los planes de su política panamericanista, los años de la guerra y los que siguieron a ella se caracterizan por la aplicación de una serie de medidas político-económicas que tendrán un impacto importante en la penetración económica de las EE. UU. en el hemisferio occidental, forzando a los países latinoamericanos a adoptar una posición subordinada dentro de la política económica norteamericana. Esto respondía. como ya ha sido indicado, a la necesidad objetiva de la economía de este país de abarcar nuevos mercados para el creciente éxcedente de sus productos y capitales.

Los perspectivas que se le abren a los Estados Unidos con su nueva posición como potencia económica mundial renuevan sus impulsos por ganar nuevos mercados. Al respecto, $\mathrm{F}$. C. Schwedtman, del National City Bank de Nueva York, señalaba, en diciembre de 1916, que el desarrollo de mercados extranjeros hace imperativo una maquinaria financiera vastamente expandida. no sólo para ofrecer todas las facilidades comerciales y bancarias posibles a los comerciantes internacionales sino también para presentar canales estables a través de los cuales la inversión de capitales pueda fluir a los paises prestatarios. Luego agregaba que los países latinoamericanos necesitan generosas cantidades de capital y compradores para sus productos y que, pese a que países europeos como Inglaterra y Alemania controlaban prácticamente la mayor parte del comercio y de las inversiones en esta región. la guerra había causado una fuerte contracción de los créditos y préstamos efectuados anteriormente por Europa, a la vez que los Estados Unidos con una rápida apreciación de los beneficios resultantes de la cooperación con los países latinoamericanos, pueden llenar el vació dejado por los países europeos en cuanto al abastecimiento de mercancías y capitales (F. C. Schwedtman. 1917:239 y 243).

Según las evaluaciones de ese autor, los países sudamericanos necesitaban de capitales extranjeros para su desarrollo, y las oportunidades para la construcción de carreteras, de líneas mercantes de navegación, almacenes de depósitos, muelles, plantas eléctricas y de gas, etc. eran casi ilimitadas. Además consideraba que los ingresos provenientes de las inversiones eran considerables, señalando, en este contexto, que las cifras, disponibles sobre las inversiones de Gran Bretaña en toda Sudamérica parecían ser del orden de los cinco mil millones de dólares, en préstamos públicos, servicios públicos de corporaciones, bancos y sistemas de transportes. Estimaba, al mismo tiempo, que el ingreso proveniente de esa masa de inversiones era de 250 millones de dólares, lo que equivalía a una renta ligeramente superior al $5 \%$, que correspondía casi al pago total de las importaciones británica de Sudamérica (F. C. Schwedtman, 1917:24344).

\section{LA INTERNATIONAL HIGH COMMISSION}

Los hechos más significativos de esa política norteamericana, que incidían directamente en el nuevo papel económico a desempeñar por las naciones latinoamericanas, los constituyeron las conferencias financieras panamericanas de los años 1915 y 1920, y la constitución de la International High Commission como uno de los resultados más relevantes de la Conferencia Financiera de 1915.

Esta Primera Conferencia Financiera Panamericana, patrocinada por el gobierno 
norteamericano. perseguía en general que el gobierno estadounidense facilitara la extensión de amplios créditos para el comercio interamericano y que proveyera de adecuadas facilidades de transporte marítimo para efectuar ese comercio. Asimismo, se proponía que los bancos de la Reserva Federal establecieran agencias conjuntas en cada uno de los países latinoamericanos, y se urgía al gobierno norteamericano a que patrocinara conferencias financieras anuales. La creación de la High Commission en la primera de estas conferencias puede ser interpretado como un intento de los panamericanistas progresistas para promover un medio legal y financiero favorable a la integración y al crecimiento económico interamericano, que proporcionaría un cuerpo político, aunque semioficial, que proseguiría el trabajo de las diversas conferencias panamericanas y uniría al gobierno con hombres de negocios que puedan resolver problemas al margen de los tradicionales canales diplomáticos (R. N. Seidel, 1973:72-77).

Los objetivos principales de la Conferencia Financiera en esta sentido se expresaban a través de una campaña destinada a formular leyes comerciales y financieras uniformes y a la solución pacífica de las disputas comerciales internacionales. Según los expertos, los alcances obtenidos por los Estados Unidos en materia de estandarización de un sistema monetario, bancario y financiero serviría como un modelo que ayudaría a superar las diferencias regionales y a alentar el comercio interregional y el flujo de capitales. Estas metas fueron concretadas en siete puntos (R. N. Seidel, $1973: 79$ y $88-89$ ):

1. Establecimiento de un valor estándar

2. Estandarización de las órdenes de intercambio, documentos comerciales y órdenes de carga.

3. Clasificación uniforme de las mercancías, regulaciones aduaneras, certificados consulares, etc.

4. Regulaciones uniformes para los agentes viajeros.

5. Protección común de las marcas comerciales, patentes y propiedad literaria (derechos de autor).

6. Establecimiento de una tasa baja uniforme de franqueo y de órdenes de cambio de monedas y de encomiendas postales entre los países americanos.

7. Extensión del proceso de arbitraje de las disputas comerciales.

Estos puntos fueron adoptados, con cambios menores, en la primera reunión de la High Commission efectuada en Buenos Aires, en Abril de 1916. Para los banqueros estadounidenses tenía un carácter prioritario el establecimiento del estándar oro como una condición indispensable para que hubiese confianza en las políticas monetarias y fiscales por parte de los otros Estados, porque tales estándares facilitarían particularmente los pagos internacionales. Y, aunque en la primera reunión general de la Comisión se admitió la imposibilidad de una reforma inmediata de los sistemas monetarios latinoamericanos se insistió en que se podrían dar dos pasos fundamentales: el establecimiento del estándar oro y la fundación de un Banco Central en cada país.

El estándar oro implicaba tasas estables de intercambio para las monedas de los diferentes países adherentes a él. Eliminaba las preocupaciones de los comerciantes con relación a los cambios en los precios de las monedas y dejaba a la oferta y la demanda la determinación de los precios de los productos. Para esto la actividad monetaria de la International High Commission se centró en Sudamérica, especialmente en Argentina. Brasil. Chile y Uruguay, considerados como las países más estables y económicamente más progresistas de los Estados Latinoamericanos, en tanto que los banqueros privados norteamericanos y el Departamento de Estado asumirían los roles líderes en las relaciones financieras con el resto de América Latina (R. N. Seidel, 1973:90-91, 94-95).

La interferencia que significó la Primera Guerra Mundial y el ingreso de los EF. UU. en 
alla en 1917 en sus planes delineados. no alteró. sin embargo, el comercio y los objetivos de desarrollo del Panamericanismo Progresista. Tres cuestiones basicas debieron ser resueltas: la santidad de capital norteamericano que estaría disponible para inversiones en créditos o en uso productivo a largo plazo y en servicios públicos en América Latina: la política a seguir por el gobierno con relación a tales flujos de capitales: y la forma como los flujos de capitales serían alentados, dadas las limitaciones impuestas por las primeras dos cuestiones.

En orden a resolver estos problemas el gobierno norteamericano fijó prioridades y adoptó algunas medidas inmediatas. La primera de ellas fue el mejoramiento de las facilidades bancarias $\because$ de créditos para el comercio: se autorizó. en este sentido. a los bancos norteamericanos que solicitasen el establecimiento de filiales en otros páses. siendo el National City Bank el primero en establecer una filial en Buenos Aires en el año 1914. En cuanto a la política do inversiones este campo fue monopolizado en un comienzo por los bancos privados, entre ellos. el mencionado Vational City Bank que ya a comienzos de la guerra había efectuado inversiones en bonos del gobierno argentino por un total de 40 millones de dólares y que había comenzado à tener en consideración la posibilidad de efectuar una inversión similar en Chile. Por su parte, la International High Commission abogaba constantemente por la expansión de los créditos a América Latina como una forma de competir exitosamente con los sectores mercantiles europeos (R. N. Seidel, 1973: 99, 106-7, 113-4).

Paralelamente a estas medidas el gobierno estadounidense ayudó directamente a los sectores vinculados al comercio exterior de los Estados Unidos mediante la promulgación del Acta WebPomerane de abril de 1918. A través del Acta sus agencias de exportación quedaban liberadas de la aplicación de la legislación anti-trust norteamericana. Esta ley, promulgada como respuesta a la competencia europea de postguerra en los mercados mundiales y, en parte, dirigida a los mercados de las regiones subdesarrolladas. tuvo resultados significativos en los años veinte. Las asociaciones registradas bajo esta ley que, en el año 1919, habían enviado al extranjero menos del uno por ciento del valor total de las exportaciones norteamericanas se elevaron al $13.8 \%$ del total de las ventas estadounidenses en el año 1929 (R. N. Seidel, 1973:116; C. Lewis, 1938:186).

La Segunda Conferencia Financiera Panamericana. efectuada en Junio de 1920 y patrocinada por el Departamento del Tesoro de los EE. UU.. tenía como propósito principal determinar las posibilidades concretas para las inversiones norteamericanas en la región latinoamericana en un momento cuando las industrias y bancos estadounidenses daban prioridad a las necesidades europeas. De acuerdo al Secretario del Tesoro de los EE. UU.. Carter Glass, las precondiciones para las inversiones en América Latina debían ser creadas mediante la generación de una completa atmósfera de confianza en la estabilidad y buen estado de los gobiernos latinoamericanos, insistiéndose al respecto en la necesidad de efectuar reformas en los sistemas financieros y del establecimiento del estándar oro. Estos esfuerzos económicos de la política del Panamericanismo Progresista fueron integrados. en los años veinte, dentro de una política norteamericana. orientada globalmente. de reconstrucción y desarrollo, de modo que durante esa década el Departamento de Estado promovió activamente la reforma financiera en América Latina y sirvió para supervisar legalmente los intereses norteamericanos en el extranjero (C. Lewis, 1938:125-26, 203).

En la consecución de esta política la Unión Panamericana desempeñó un rol secundario y la Interamerican High Commission cumplió la útil función de promover la compatibilidad entre las leyes comerciales de los países americanos. Ya en la Quinta Conferencia de Estados Americanos. celebrada en Santiago de Chile en marzo de 1923. se notó una cierta reluctancia por parte de los 
países latinoamericanos sobre el papel de la Unión Panamericana en cuanto a materias económicas. Varios de estos países estimaban que las cuestiones económicas eran parte de sus asuntos internos : Chile. en particular, deseaba que la Conferencia sirviera en alguna medida como una plataforma para el desarme latinoamericano.

Todo parece indicar que en algunos círculos económico-políticos latinoamericanos todavía existía desconfianza respecto a las verdaderas intenciones de los Estados Unidos con su programa de inversiones en los países de esta región. A esto debe haber contribuido la experiencia de Bolivia que, por un préstamo de 29 millones de dólares que recibió de los Estados Unidos en el año 1922 para cumplir con algunas obligaciones contraídas con el extranjero y para construir carreteras y ferrocarriles, debió dar una serie de garantías a los EE. UU. que, en la práctica, significaban la subordinación y el control económico de ese país a los intereses norteamericanos (H. Faulkner 1945:761).

Fueron entonces estos instrumentos convencionales del gobierno norteamericano y sus casas financieras los encargados de llevar a la práctica la política de inversiones de capital y de efectuar las reformas financieras propiciadas por los Estados Unidos en los países latinoamericanos, recurriendo muchas veces, para el logro de esos objetivos, al soborno de políticos o de influyentes personalidades de Gobierno (Según C. Lewis, en un momento de la década de 1920, habían 29 representantes de casas financieras norteamericanas en Colombia tratando de negociar préstamos para el Gobierno Colombiano, para los departamentos y para otros posibles prestatarios. En Perú, un grupo de exitosos promotores estadounidenses incluía a un peruano, el hijo del presidente de la República, quien posteriormente fue juzgado por los tribunales de su país y convicto de enriquecimiento ilegal. En Cuba al yerno del Presidente se le proporcionó una bien pagada posición en la rama cubana de un Banco Norteamericano durante la mayor parte del tiempo que el Banco estuvo compitiendo entre otros bancos estadounidenses para financiar al Gobierno Cubano (C. Lewis, 1938:337-78). En otras ocasiones dieron también un apoyo abierto o encubierto a gobiernos dictatoriales que apoyaban esas reformas y a agencias consultores, como la misión Kemmerer, que se encargaban de estudiar y analizar el sistema financiero del país en cuestión y de efectuar las reformas financieras propuestas por los Estados Unidos.

\section{LA MISIÓN KEMMERER}

Los trabajos de la Misión Kemmerer en diversos países latinoamericanos tenían como propósito. sostiene R. Seidel, la estabilización de las monedas nacionales, de los sistemas bancarios y de la economía, y la extensión internacional de las instituciones norteamericanas, el comercio y las finanzas. En este sentido E. W. Kemmerer actuó como consultor financiero para los gobiernos de México (1917) y Guatemala (1919, 1924), y encabezó las misiones financieras en Colombia (1923, 1930), Chile (1925), Ecuador (1926-27), Bolivia (1927) y Perú (1931) (R. Seidel, 1972: 521-22).

Aunque las soluciones monetarias y financieras propuestas por la Misión Kemmerer variaban de un país a otro de acuerdo a las específicas circunstancias económico-financieras y socio-políticas de cada uno de ellos, es posible sostener que las reformas propuestas incluyeron ítems similares en todas ellas: proyectos para el establecimiento de Bancos Centrales y una nueva ley monetaria; planes para la supervisión de bancos y del presupuesto gubernamental, y programas para mejorar la recolección de impuestos, establecer un sistema de tarifas más eficiente y supervisar la administración de los ferrocarriles (R. Seidel. 1972: 542). 
Ya en el año 1916 E. M. Kemmerer expuso en un artículo (E. M. Kemmerer, 1916: 69-72) las razones que él consideraba pertinentes para intentar el establecimiento de una unidad monetaria panamericana, a saber:

a) Bajo un plan tal los precios corrientes en la región latinoamericana serían cotizados en términos de unidades monetarias que serían comprensibles para las gentes de todos los países, lo cual facilitaría y agilizaría las transacciones comerciales.

b) Las operaciones de intercambio con el extranjero serían simplificadas haciéndolas más comprensibles para el hombre de negocios.

c) Otra ventaja se hallaría en el hecho de que se haría menos frecuente la fundición de monedas de una nación para convertirlas en barras de oro que posteriormente deberían ser nuevamente fundidas para transformarlas en monedas de oro de otra nación. Estos gastos se eliminarían bajo una unión internacional en la cual la unidad monetaria de cada una de las repúblicas latinoamericanas sería igualada a aquellas de todas las otras, y en la cual las monedas de oro estandarizadas de cada una serían reconocidas por todas ellas.

d) Una cuarta ventaja sería el estímulo que un tal ordenamiento daría al mejoramiento de los sistemas monetarios de las naciones americanas ('Está bien tener una buena moneda en casa, pero para nuestro comercio internacional es igualmente importante que haya una buena moneda en el extranjero')

e) Una quinta ventaja, señala Kemmerer, radicaría en el hecho de que un plan tal promovería fuertemente el ideal de la Unión Panamericana. La existencia de un estándar monetario unificado, con monedas de oro circulando con los emblemas del panamericanismo a lo largo de los dos continentes, seria un símbolo perpetuo del ideal panamericano.

A la vez Kemmerer estimaba que una de las ventajas derivadas de las anteriores sería el estímulo que tal unidad monetaria daría a la inversión de capitales extranjeros en los países menos desarrollados. Precisamente este último objetivo será el factor motriz para el establecimiento del estándar oro en los países sudamericanos en vez de la consecución del ideal panamericanista y en vez de la Unión Panamericana dicho objetivo será alcanzado por el Departamento de Estado estadounidense y las casas financieras y consultoras de ese país.

La Misión Kemmerer llega a Chile cuando ya se ha conformado un escenario económico, político y social que, no obstante ser bastante favorable a esas medidas monetarias, financieras y administrativas, se encontraba en medio de una coyuntura política en la cual las fuerzas armadas desempeñaban un papel decisivo en las decisiones políticas del país.

Desde el punto de vista de las relaciones comerciales, el intercambio entre Chile y los Estados Unidos se había elevado notoriamente. Ahora Norteamérica era el principal socio comercial de Chile: las importaciones chilenas desde los Estados Unidos correspondían en 1929 al 32\% del total de sus importaciones (contra el 17\% en 1913), le seguía Gran Bretaña con el $21 \%$ (contra el $35 \%$ en 1913) y luego Alemania con el 15\% (contra el 25\% en 1913); a su vez las exportaciones chilenas a los Estados Unidos en el año 1929 había aumentado al $38 \%$ (contra el 21\% en 1913); a Gran Bretaña había disminuido al $21 \%$ (del 38\% en 1913) y a Alemania también había decrecido a un $13 \%$ (de un $21 \%$ en 1913), intercambio favorable a los Estados Unidos desde que la Misión Kemmerer había aplicado sus medidas desde 1925 en adelante (P. Drake, 1984:32). En cuanto a 
las inversiones directas de los Estados Unidos en Chile éstas ascendían, en la década de 1930, a la suma de 484 millones de dólares de cuyo total casi las cuatro quintas partes se encontraban empleadas en la industria minera (H. Villablanca, 1979:25).

Puede decirse que la llegada de la Misión Kemmerer a Chile fue bienvenida por amplios sectores sectoriales de la población que veían en ella la estabilización monetaria y la tranquilidad social que podrían poner fin a las décadas de continua depreciación monetaria e inflación. La iniciativa comenzada por A. Alessandri fue concretada por las Juntas Militares que le reemplazaron en 1924-25, de modo que Kemmerer encontró un gobierno autoritario dedicado a reacondicionar los sistemas administrativos y financieros básicos de la nación. Después de permanecer poco menos de dos meses en Chile, dice P. Drake, Kemmerer entregó sus recomendaciones, esto es, sugirió medidas detalladas para la creación de un Banco Central, el establecimiento del padrón oro, medidas bancarias generales, instrumentos negociables y seguros comerciales, proponiendo también cambios en los créditos de comercio y seguros comerciales. Para las reformas fiscales, la Misión presentó proyectos sobre el presupuesto, una contraloría general y contabilidad estatal, ferrocarriles nacionales, deudas públicas, una oficina de impuestos internos e impuestos a los ingresos, bienes raíces, estampillas y papel sellado, tabacos, espectáculos públicos e hipódromos, clubes de socios y sobre exportaciones de minerales de hierro, todo lo cual fueron virtualmente puestos en ejecución, sin modificaciones serias, antes que la Misión abandonara el país (P. Drake, 1984:39-41).

En algo menos de tres décadas los Estados Unidos había completado un ciclo que se inició con un estudio detenido y realista de sus deficiencias para hacer llegar a los mercados sudamericanos el producto excedente del enorme desenvolvimiento económico que experimentaba desde la década de 1870 en adelante, seguida por una ofensiva diplomática, de inversiones y comerciales que lo colocaron en el primer lugar de sus relaciones comerciales con América Latina y Chile en particular, desplazando a Gran Bretaña y otras potencias europeas.

\section{BIBLIOGRAFÍA}

Barreda, Felipe (1927)

Barros Arana, D (1892)

Caruso, John A. (1951)

Cassey, Clifford B. (1932)

Clow, Frederick R. (1893)

Downs, William C. (1912)
"Latin American Opposition to the New Monroeim", en Current History, March 1927.

Historia Jeneral de Chile, Santiago, vol 16.

"The Pan American Railway", en Hispanic American Historical Review, N"4.

"Creation and Development of the Pan American Union", en Hispanic American Historical Review, vol 32.

"South American Trade", en The Quaterly Journal of Economics, vol 7.

"The Commission House in Latin American Trade", en The Quaterly Journal of Economics, vol 26. 
Drake, Paul (1984)

Dunn, Robert (1926)

Emory, Frederick (1904)

Faulkner, Harold (1951)

Faulkner H. (1945)

González C, Pablo (1978)

Kahler, Hugh (1911)

Kaufman, Burton (1971)

Kemmerer, E. W. (1916)

Kinley, David (1911)

Lewis, Cleona (1938)

Loomis, Francis (1903)

Molina H., Evaristo (1918)

Nearing, S. y Freeman, J, (1969)

Ramírez N. Hernán (1966)

Rippy, Fred (1949)

Robertson, William (1923)

Schoff, Wilfred H. (1911)

Schwedtman, F. C. (1917)
"La Misión Kemmerer a Chile: Consejeros Norteamericanos, Estabilización y Endeudamiento, 1925-1932", en Cuademos de Historia. Departamento de Ciencias Históricas, Universidad de Chile, N"4. Julio 1984.

American Foreign Investments. Washington.

"Causes of our Failure to Develop South American Trade", en The Annals, January - June.

The Decline of Laisses Faire 1897-1917, N. York.

American Economic History, N. York.

"Las Intervenciones Extranjeras y la Crisis del Imperialismo" en Araucaria, Madrid. N'2.

"Current Misconceptions of Trade with Latin América" en The Annals, vol 37. N 3.

"United States Trade and Latin America: The Wilson Years", en The Journal y America History, vol 43, September 1971

"A Proposal for Panamerican Monetary Unity", en Political Science Quarterly, vol 31, N" I

"The Promotion of Trade with South América". en The American Economic Review. vol 1.

America's Stake in International Investments, Washington.

The Position of the United States on the American Continent -some phases of the Monroe Doctrine", en "The Annals of the American Academy of Political and Social Science, vol XXII, N"I.

"La Doctrina Drago", en Anales de la Universidad de Chile, tomo CXLII.

Dollar Diplomacy. N. York.

Historia del Imperialismo en Chile, La Habana.

"Investment of Citizens of the United States in Latin America"; en The Journal of Business. January 1949.

Hispanic-American Relations with the United States, N. York.

"Investments of American Capital in Latin America", en The Annals. vol 37. N 3.

"Lending our Financial Machinery to Latin America", en The American Political Science Review, N' 2, May. 1917. 
Seidel, Robert N. (1973)

Seidel, R. N. (1972)

Shipstead, Henrik (1927)

Sorrell, Lewis C. (1916)

Soule, George (1947)

Tower, Walter S. (1916)

U.S. Departament of Commerce (1930)

U.S. Departament of Commerce (1922)

Véliz, Claudio (1961)

Villablanca Z. Hernán (1979)
Progresive Panamericanism: Development and United States Policy Toward South America. 1906 - 1931: Thesis presented to the Faculty of the Graduate School of Cornell University for the Degree of Doctor of Philosophy.

"American Reformes Abroad: The Kemmerer Mission in South America, 1923-1931", en The Journal of Economic History, vol XXXII, N 2 .

"Dollar Diplomacy in Latin America", en Current History, September 1927.

"Dislocations in the Foreign Trade of the United States Resulting from the European War", en Journal of Political Economy, vol. 24.

Prosperity Decade. 1917-1929. London.

"The Third International Conference at Rio de Janeiro, 1906". (1932). en Hispanic American Historical Review, vol 12.

"Buying South American Goods as a Factor in selling to South America". en The Journal of Political Economy, vol 24.

Foreing Commerce and Navigation of the United States for the Calendar Year 1930.

Foreing Commerce and Navigation of the United States for the Calendar Year 1922.

Historia de la Marina Mercante de Chile, Santiago.

"Las Inversiones de los Estados Unidos en Chile, 1950-1970", en Desarrollo Indoamericano, Colombia, $\mathrm{N} 47$. 